Fourth International Conference on Sustainable Construction Materials and Technologies http://www.claisse.info/Proceedings.htm

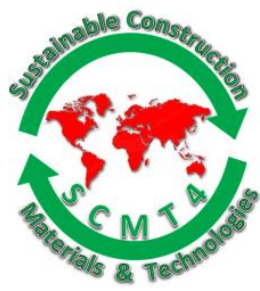

SCMT4

Las Vegas, USA, August 7-11, 2016

\title{
Vascular Systems for Biomineralisation in Granular Materials
}

\author{
Kwong Yu Ho ${ }^{1 a}$, Navdeep K. Dhami ${ }^{1 b}$, and Abhijit Mukherjee ${ }^{1 \mathrm{c}}$ \\ ${ }^{1}$ Department of Civil Engineering, Curtin University, Bentley, Western Australia 6102. \\ ${ }^{1 b}$ Email: 〈navdeep.dhami@curtin.edu.au>, ${ }^{1 c}$ Email: 〈abhijit.mukherjee@curtin.edu.au>
}

\begin{abstract}
Civil infrastructure is being built all over the world at an ever increasing pace using cement. Although use of Ordinary Portland Cement has resulted in strong and durable structures, its high embodied energy and emission of poses a great sustainability challenge. Recent research has found that nature produces high performance cement sustainably. Biomineralisation, more specifically, microbially induced calcium carbonate precipitation (MICP) is emerging as a technique for producing sustainable cement. Although the technique shows great promise there are several research questions and paramount among them is the dichotomy of having to feed the cementation fluids through the same pore channels that that it is supposed to fill. This paper investigates a few vascular systems for delivering the cementation fluid that are similar to the natural circulatory systems. Three major factors, grain size, method of curing and stability of grain structure have been studied. Both non-destructive and destructive tests have been performed to determine the mechanical properties. It reveals that the grain structure can be optimised for maximum carbonate deposition rate and the proposed vascular system improves the efficacy of cementation and economises cementation fluids.
\end{abstract}

\section{INTRODUCTION}

Reinforced concrete is arguably the most used manmade material worldwide as it is the material of choice for the construction of rapidly developing infrastructure of the world. Evidently, it has made a major contribution in achieving the millennium development goal of the United Nations (UN) that resulted in the rising prosperity of the emerging economies. The sustainability score of reinforced concrete, especially its binder, cement, is not so bright. According to CEMBUREAU (2015) in 2014, 4.3 billion tonnes of cement was produced worldwide and its demand is growing at around $10 \%$. When one reconciles with the fact that each ton of cement releases almost an equal quantity of carbon dioxide in the atmosphere one starts to appreciate the enormity of the problem. Evidently, the reward of achieving the UN millennium development goal has come at a price of the looming prospect of irreversible climate change. A paradigm shift in the construction materials and technologies is imperative for achievement of UN's more recent climate change goal. Nature, on the other hand, builds with negligible consumption of energy. Natural accretionary formations (sandstones, stalagmites and stromatolites) and ceramics (mollusc shell, sponge spicules, and diatoms) are excellent examples that are able to meet the performance standards of modern construction materials while remaining sustainable (Achal et al. 2015; Rusznyak et al. 2012; Spadafora et al. 2010). Study of synthesis of natural materials offers a clue towards sustainable construction. 
MICP has recently emerged as a potential candidate for producing binders in construction materials by closely emulating the natural processes. It is gaining momentum in civil engineering as a highly sustainable and carbon negative building material technology (Dhami et al. 2013). Inspired from natural geological formations such as sandstones, anthills, coral reefs, this technology has been explored for improvement in strength (Achal et al. 2012), durability (Achal et al. 2011), porosity and permeability of a range of granular (Castanier et al. 1999) and porous construction materials (Dhami et al. 2012). Two most common benefits of MICP are: a) aggregation of granular materials wherein microbial carbonates bind the grains together; and $b$ ) it alters the pore structures of materials and impedes diffusion of deleterious substances (Dhami et al. 2016) ). The major advantage of the process is that the carbonates are formed at ambient temperature with very little energy and production of any greenhouse gases (Dhami et al. 2012). Improvements of soil mechanical properties by MICP have been successfully demonstrated by a number of researchers (Dejong et al. 2013). Several studies have confirmed that MICP bears the potential to alter soil characteristics leading to increased shear strength and stiffness, while maintaining the permeability (Whiffin et al. 2007). In our previous studies we reported significant improvement in strength, permeability and durability properties of bricks, sand columns and concrete with application of microbial calcite (Achal et al. 2009; Dhami et al. 2012; Dhami et al. 2012).

In MICP, metabolic activities of microbes in presence of a substrate and a source of calcium ion gives rise to nucleation and growth of calcium carbonate crystals at the junctions of granular materials such as sand and as a result, binds them together. Although there are a few variations, the popular process in MICP is based upon utilisation of aerobically cultivated bacteria with high urease enzyme activity which can hydrolyse the urea intra-cellularly to $1 \mathrm{~mol}$ of ammonia and $1 \mathrm{~mol}$ of carbonate to further form $1 \mathrm{~mol}$ of ammonia and carbonic acid.

$$
\begin{aligned}
& \mathrm{CO}\left(\mathrm{NH}_{2}\right)_{2}+\mathrm{H}_{2} \mathrm{O} \stackrel{\text { bacteria }}{\longrightarrow} \mathrm{NH}_{2} \mathrm{COOH}+\mathrm{NH}_{3} \\
& \mathrm{NH}_{2} \mathrm{COOH}+\mathrm{H}_{2} \mathrm{O} \longrightarrow \mathrm{NH}_{3}+\mathrm{H}_{2} \mathrm{CO}_{3}
\end{aligned}
$$

In the presence of calcium ions, most commonly in $\mathrm{CaCl}_{2}$, calcium carbonate $\left(\mathrm{CaCO}_{3}\right)$ forms throughout the substrate matrix as:

$$
\mathrm{Ca}^{2+}+\mathrm{CO}_{3}^{2-} \longrightarrow \mathrm{CaCO}_{3}
$$

A number of factors such as concentrations of calcium and dissolved inorganic carbon, $\mathrm{pH}$, availability of nucleation sites determines the quantity and quality of MICP (Hammes and Verstraete 2002). To deposit at the inter-granular spaces or in the pores, the cementation fluid (CF) must be delivered at those locations in adequate quantity. Conversely, the same channels are filled due to cementation. The aim of the delivery mechanism is to achieve uniform mineralisation of the desired extent throughout the substrate consuming minimum quantity of cementation fluid. The simplest delivery mechanism is pouring the cementation fluid on sand columns (Achal et al. 2009). However, flow under gravity may not be strong enough to have uniform distribution throughout the substrate. Moreover, this method has been found to create a top crust that blocks passage of the cementation fluid at later stages (Chu et al. 2012). Thus, down flushing by means of a pump has been adopted (Whiffin et al. 2007). Later, flushing up from the bottom of the column has been preferred (Cheng et al. 2013). The quantity of cementation fluid and the corresponding performance of the resulting material varies greatly with the delivery mechanism. Al Qabany (2014) reported up flushing of cementation reagents at rate of $830 \mathrm{ml} / \mathrm{hr}$ to $1.4 \mathrm{~L} / \mathrm{hr}$ from $3-5$ days using pumps at $7.5 \mathrm{psi}$ for sample size ranging from $10 \mathrm{~cm}$ to $1 \mathrm{~m}$ columns. Whiffin et al. (2007) and Montoya et al. (2012) also reported usage of pumps to pass CF into columns of varying length. Range of strength of the cemented columns vary from $200 \mathrm{kPa}$ to $30 \mathrm{MPa}$ (Montoya and DeJong 2015; Yang and Cheng 2013). Evidently, large quantities of CF has been used in these experiments that may deter large scale applications. The basic idea of using pumps is to overcome the resistance offered by the substrate. Conversely, the resistance of the substrate can be 
optimised to maintain the desired flow by gravity. Thus, an optimum combination of channel structure (determined by the grain size distribution), channel length (determined by the delivery mechanisms) and grain structure stability can be devised to manage the resistance offered by the substrate. Another parameter that might affect homogenous distribution of MICP without passing CF with pumps is prior stabilization. In this paper, we experiment with a vascular delivery system for supplying CF along with investigations of effect of grain size and prior cement stabilization. The results of this study are a step towards optimising MICP for improving consolidation of granular materials with the least use of materials and energy.

\section{EXPERIMENTAL INVESTIGATION}

Materials. The Materials consisted of a granular material (sand), a stabilizer (cement), a bacterial media and water. Manufactured sand sourced from Cook Industrial Minerals, Perth, Western Australia was used as the granular component of the mix. The particle size for the mix varied between $1.18 \mathrm{~mm}$ and $0.15 \mathrm{~mm}$. Commercially available general purpose grey cement sourced from Swan Cement, Perth, complying with AS3972, (AS 2010) and standard tap water have been utilised. Sand was autoclaved and dried prior to use.

For the biological treatment, high Urease producing microbial culture Bacillus $s p$. AM1 was isolated from Margaret caves, Western Australia. This isolate was selected for its efficacy to produce high urease and carbonic anhydrase. The bacterial culture was cultivated under aerobic conditions in Nutrient broth media as described in Dhami et al. (2016). The OD of the bacterial culture before inoculating into substrate varied between 1.5-2.0 and the urease activity was approximately $10 \mathrm{U} / \mathrm{ml}(1 \mathrm{U}=1 \mathrm{~mol}$ urea hydrolysed per minute). This was labelled as Bacterial Fluid (BF). Cementation Fluid (CF) consisted of $1 \mathrm{M}$ Urea and $1 \mathrm{M} \mathrm{CaCl}_{2}$ along with $1 \mathrm{~g} / \mathrm{L}$ Nutrient broth.

Sample preparation. Three sets of samples have been prepared for studying their impact on MICP: a) Effect of grain size; b) Curing method; and c) Cement stabilization.

\section{Effect of grain size}

The sand was shaken in a sieve shaker to separate different grain sizes. Grain size distribution of the sand was noted. The sand retained on the specified sieve was used for grain size specific samples. For mixed samples the sand as received was used. 50mL Bacterial Fluid was added into each set of varying grain sand fraction and mixed well in plastic trays. This slurry was then added into PVC columns which were tapped several times to remove any air pockets. All the columns were left to stand overnight for fixation of bacterial cells inside. All the columns were then fed with $40 \mathrm{~mL}$ cementation fluid (20 ml twice a day) for 15 days through pouring. Fresh bacterial fluid was added on the $5^{\text {th }}$ and the $10^{\text {th }}$ day.

Table1. Samples for studying the effect of grain size

\begin{tabular}{|l|l|l|l|l|}
\hline Grain size $(\mathrm{mm})$ & Sand mass $(\mathrm{g})$ & Density $\left(\mathrm{kg} / \mathrm{m}^{3}\right)$ & \multicolumn{3}{|c|}{ Sample label } \\
\cline { 4 - 5 } & & & Bacterial & Control \\
\hline 0.15 & 288 & 1471 & BG1 & CG1 \\
\hline 0.425 & 318 & 1624 & BG2 & CG2 \\
\hline 1.18 & 290 & 1482 & BG3 & CG3 \\
\hline Mixed & 325 & 1659 & BG4 & CG4 \\
\hline
\end{tabular}

Curing technique. The novelty in the present investigation is in the preparation of moulds that allow alternate modes of curing (Figure 1). The idea is to compare the effect of channel length through conventional column setup and the present vascular system. We define channel length as the minimum distance between the point of application of CF to the furthest point where it must reach. For conventional 
columns, $50 \mathrm{~mm}$ diameter PVC tubes were cut to $100 \mathrm{~mm}$ length. In the conventional method the tube was filled with the sand as in Dhami et al. 2016. The bottom face of the column was sealed with low porosity Whatman filter paper and Cementation Fluid was poured from top. In this case, CF flows through the height of the cylinder. Thus, the channel length is equal to its height (100 mm).

For the mesh moulds, an aluminium wire mesh of $0.5 \mathrm{~mm}$ openings was placed along the inside face of the PVC tube. The mesh was $1 \mathrm{~cm}$ larger in height than the tube for easy sample harvesting. Whatman filter papers were placed inside the mesh to create layer that is permeable to CF but does not allow sand grains or the bacteria to escape. The bottom of the column was covered with a mesh cap along with Whatman paper in order to avoid loss of granular material and bacteria. After pouring the sand, PVC tube was removed. In this case the CF is fed through the outer surface of the tube and the CF flows radially in the sample. Thus, the channel length is equal to the radius of the cylinder $(25 \mathrm{~mm})$.

For hollow moulds, another cylindrical mesh of diameter $5 \mathrm{~mm}$ was added to the mesh mould at its centre. This allowed simultaneous injection from the centre and spray from the outer surface. Thus, the channel length in this case reduced further to half of the difference of the inner and outer diameters of the meshes $(11.25 \mathrm{~mm})$.

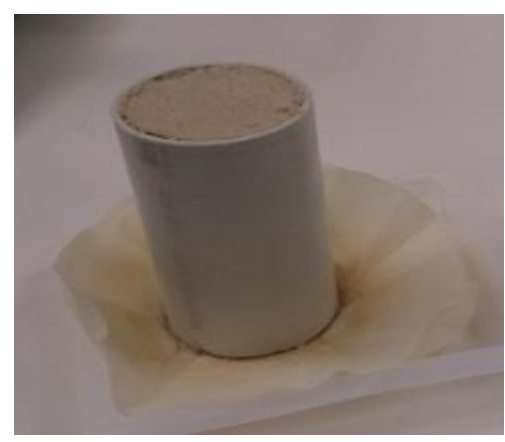

a) Solid mould

b) Mesh mould

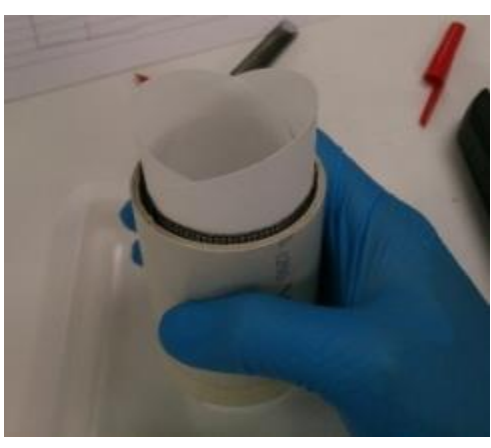

c) Hollow mould

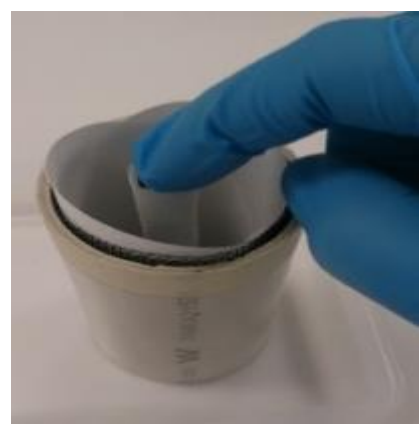

Figure 1. Details of moulds

The moulds were filled with the mixture of sand and the cementitious component (OPC or bacterial mixture). They were tapped several times for uniform compaction. The columns were left to stand overnight and PVC tubes were removed the next day. The samples were fed CF at specific rates and durations (Fig. 2a). $20 \mathrm{~mL}$ CF was added twice each day till 15 days along with supplementation of BF on $5^{\text {th }}$ and $10^{\text {th }}$ day. Three methods of feeding were used (Table 2) a) CF sprayed on the outer surface of the mesh moulds; b) $\mathrm{CF}$ was sprayed from outside while it was injected through the hollow core of hollow moulds; c) moulds immersed in CF. Fig. 2b shows a cured sample.

\begin{tabular}{|l|l|l|l|l|}
\hline \multicolumn{5}{|c|}{ Table2. Samples for studying the effect of curing technique } \\
\hline Feeding & Sand mass $(\mathrm{g})$ & Density $\left(\mathrm{kg} / \mathrm{m}^{3}\right)$ & \multicolumn{2}{|c|}{ Sample label } \\
\cline { 4 - 6 } & & & Bacterial & Control \\
\hline Surface spray & 325.2 & 1659.1 & $\mathrm{BC} 1$ & $\mathrm{CC} 1$ \\
\hline Injection & 319.4 & 1695.2 & $\mathrm{BC} 2$ & $\mathrm{CC} 2$ \\
\hline Immersion & 325.2 & 1659.1 & $\mathrm{BC} 3$ & $\mathrm{CC} 3$ \\
\hline
\end{tabular}




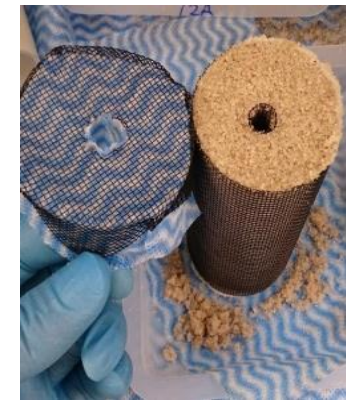

a) before curing

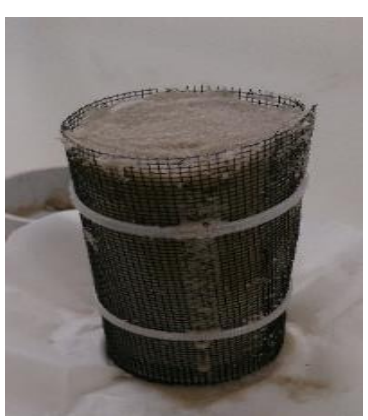

b) after curing

\section{Figure 2. Typical samples}

\section{Cement stabilization}

The next experiment investigates the effect of channel stabilization on MICP. We define stabilized channel as the one where the grains do not move as a result of flow of CF. This is achieved by mixing a small quantity of cement in the sand prior to filling the moulds. $6 \%$ cement of the weight of sand was added in this experiment. The cement hardens and holds the grains in place to offer stability of the channel. Table 3 presents the details of both bacterial and control samples with corresponding grain sizes.

All the sand columns were cured for 15 days. Then they were washed with two pore volumes of deionized water containing $50 \mathrm{mM}$ sodium chloride to rinse excess chemicals from the pore spaces. All the moulds were disassembled and the sand columns were oven dried overnight at $70^{\circ} \mathrm{C}$ for further tests.

\begin{tabular}{|l|l|l|l|l|l|}
\hline \multicolumn{7}{|c|}{ Table3. Samples for studying the effect of stabilization } \\
\cline { 5 - 7 } Grain size (mm) & Sand mass $(\mathrm{g})$ & $\begin{array}{l}\text { Density } \\
\left(\mathrm{kg} / \mathrm{m}^{3}\right)\end{array}$ & $\begin{array}{l}\text { Cement mass } \\
(\mathrm{g})\end{array}$ & \multicolumn{3}{|c|}{ Sample label } \\
\hline 0.15 & 296.8 & 1514 & 17.8 & Bacterial & Control \\
\hline 0.425 & 317.6 & 1620 & 19 & BS1 & CS1 \\
\hline 1.18 & 295.6 & 1508 & 17.7 & BS3 & CS2 \\
\hline Mixed & 327.1 & 1668 & 19.6 & BS4 & CS4 \\
\hline
\end{tabular}

Measurement Methods. Mechanical tests were performed both non-destructively and destructively. For non-destructive tests a JSR pulser-receiver system along with a pair of $500 \mathrm{kHz}$ Panametrics transducers were used in primary wave mode (Figure 3a). In this system, the wave velocity is measured to have an estimate of the degree of cementation. As the cementation progresses the material hardens and thus, the wave propagates faster. JSR DPR300 Ultrasonic pulser-receiver system was adjusted in transmission mode at $+10 \mathrm{~V}(66 \mathrm{~dB}$ gain) with $30 \mathrm{kHz}$ square wave and $1 \mathrm{kHz}$ high pass filter to remove background noise. The transducers were held securely at the two ends of the sample after applying vacuum grease to ensure coupling between the transducer face and specimen surface. The waveform was recorded on a Tektronix oscilloscope. The time difference between the trigger at the transmitter and the appearance of the first peak in the receiver was noted. The distance between the transducers was divided by the time of flight to obtain the pulse velocity. 


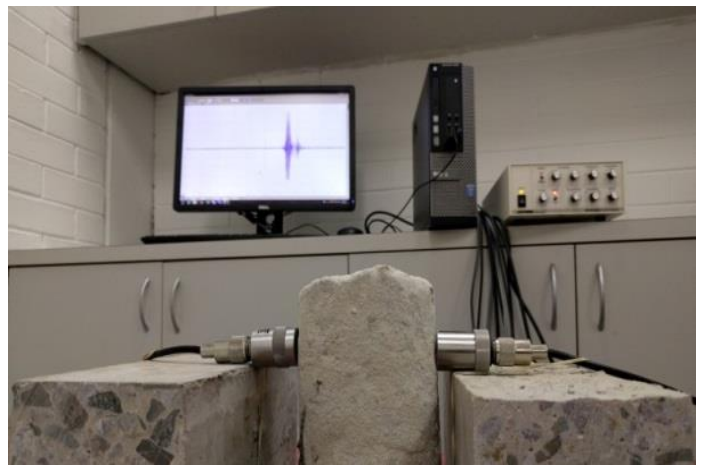

a. UPV test

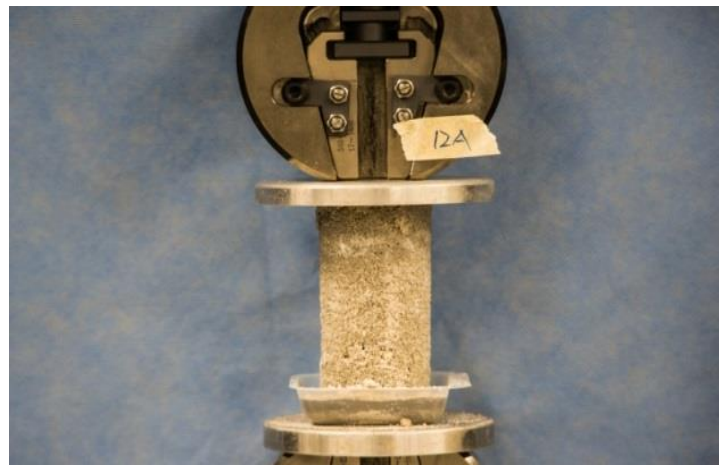

b. UCS test

Figure 3. Non-destructive and destructive tests

Unconfined compression strengtn (ULD) tests were perrormed on all specimens in accordance with ASTM D2166M-13. A Shimadzu AGS-10kNXD precision universal tester was used for this purpose (Figure 3b). The specimen was placed vertically between the loading platens. A thin layer of sand was used on the top and bottom of the specimen for avoiding any tilt and local stresses. The loading rate was $1 \mathrm{~mm}$ per minute and the test was strain controlled with a rate of $1-2 \%$ strain/min. The test was continued until failure and the stress-strain behaviour of each specimen was recorded.

After the UCS test, calcite concentration measurements were performed following the methods of Achal et al. (2009). One gram of the specimen was collected from three areas of each specimen both along the length and diameter. The samples were crushed, mixed and dry weight was taken. They were then washed with $5 \mathrm{M} \mathrm{HCl}$ and dry weights were obtained to determine the amount of carbonates.

To analyse the morphology and composition of cemented materials scanning electron microscopy (SEM) and X-ray dispersion spectrum (EDS) analysis were conducted. The samples for SEM were completely dry and pre-coated with $5 \mathrm{~mm}$ platinum. The samples were observed under SEM at $15 \mathrm{kV}$ setting. For XRD, the samples were finely grounded. XRD spectra were obtained using an X'Pert PRO diffractometer with a Cu anode ( $40 \mathrm{kV}$ and $30 \mathrm{~mA}$ ), and scanning from $3^{\circ}$ to $60^{\circ} 2 \theta$. The components of the sample were identified by comparing them with standards established by the International Centre for Diffraction Data. All experiments were performed in triplicates and the analyses were performed using GraphPad Prism (5.0) ${ }^{\circledR}$ software.

\section{RESULTS AND DISCUSSIONS}

When the samples were demoulded the control samples without any cementation crumbled immediately while cemented samples, both with OPC and MICP retained their cylindrical shape. This demonstrates the ability of MICP to aggregate loose sand.

\section{Effect of grain size:}

Figure 4 represents the effect of MICP on varying grain size specimens through UPV, UCS and calcite content. The wave velocity test results reveal that the velocity ranged from $290 \mathrm{~m} / \mathrm{s}$ (BG3) to $365 \mathrm{~m} / \mathrm{s}$ (BG2) (Figure 4a). De Jong et al. (2012) reported that shear wave velocity of $400 \mathrm{~m} / \mathrm{s}$ corresponds to high strength. In case of bio bricks treated for 28 days with 3-5 treatments per day, De Jong et al (2014) reported p wave velocities in the range of 1500-3000 (m/s). While UPV for BG1, BG2 and BG4 varied within a narrow range BG3 had a noticeably slower velocity. This showed poor consolidation in high grain size specimens compared to others. It shows that BG2 with a grain size of $0.425 \mathrm{~mm}$ achived the highest consolidation. 

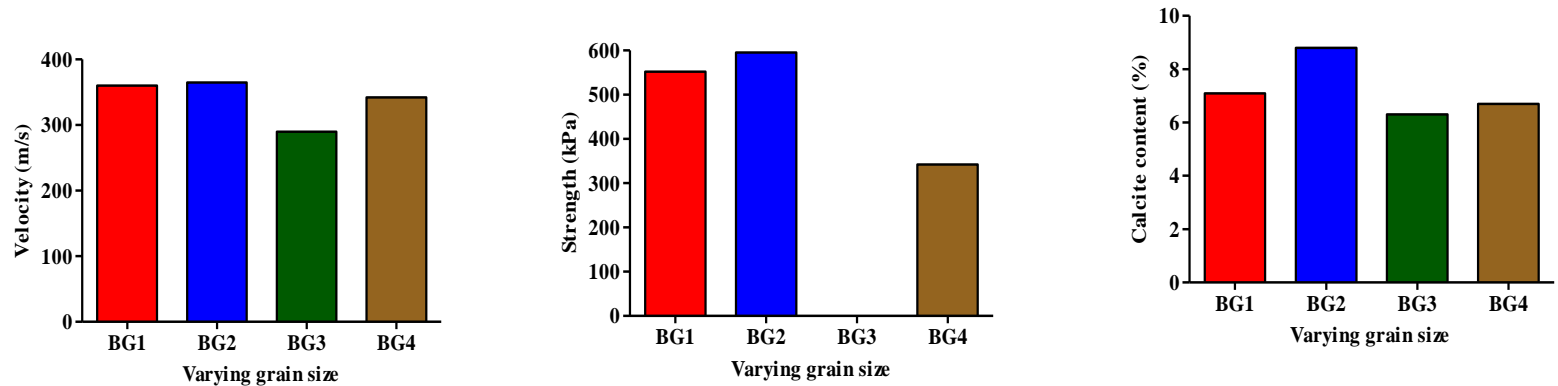

Figure 4. Effect of varying grain size on MICP a) UPV b) UCS c) Calcite content

The UCS test showed similar trend as in UPV. Here too BG2 had the highest UCS followed by BG1 and BG4. BG3 collapsed at a rather low stress and the result was discarded. The results show that UPV can be calibrated to UCS in aggregated sans columns. Thus, strength of this material can reliably be determined by non-destructive means. The range of strengths varied between $375 \mathrm{kPa}$ and $595 \mathrm{kPa}$, emphasizing the powerful effect of grain size on strength. Bernardi et al (2014) found similar improvement in strength of bio bricks in the range of $121 \mathrm{kPa}$ to $910 \mathrm{kPa}$ over a curing period of 28 days. In this case, highest strength $(595 \mathrm{kPa})$ was achieved in case of $0.425 \mathrm{~mm}$ grain size (BG2). BG1 with a finer $0.15 \mathrm{~mm}$ grain size withstood $10 \%$ loear stress $(540 \mathrm{kPa})$. The mixed grain size columns, BG4, failed at considerably lower stress $(375 \mathrm{kPa})$.

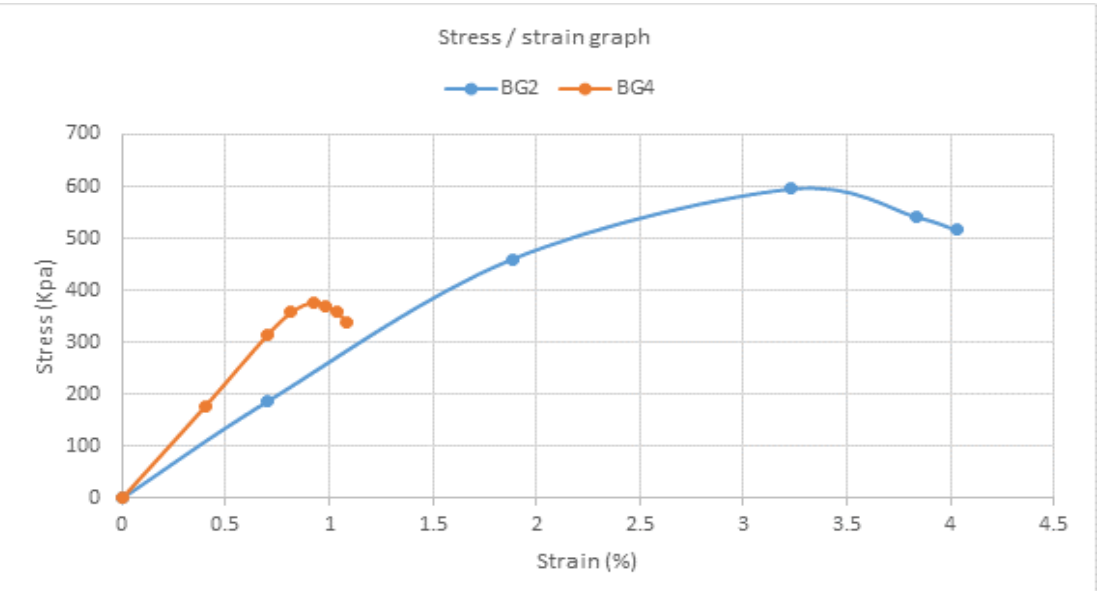

Figure 5. UCS (Stress vs strain) plot of BG2 and BG4 sand column

The stress-strain graph of two representative sample types is plotted in figure 5. Great variation in the ultimate strain is noticed in the two samples. This is due to the difference in failure modes. BG2 fails gradually through development of vertical microcracks that coalesce into a vertical crack through the centre of the specimen triggering global failure. Other samples fail more suddenly due to the collapse of the bottom half of the sample. This indicates a weaker bottom half of these samples. It may be kept in mind that the cementation fluid was fed through the top of these samples. It has been reported that the facultatively anaerobic bacterial cells grow at higher rates at the top surface due to the presence of oxygen and nutrient leading to higher deposition of carbonates in the pore spaces (Stocks-Fischer et al. 1999). The carbonate specification narrows or blocks the pore spaces resulting in deficient supply of nutrients in the bottom half of the column. Thus, the bottom half in considerably weaker than the top half of the column. This is a weakness of column feeding that we shall try to alleviate through the vascular feeding. 
The hypothesis of variable calcite deposition along the height of the column can be verified by measuring the calcite content. It may be noted that calcite in the specimens also followed the trend of the previous two tests wherein higher calcite content was noticed in case of $0.425 \mathrm{~mm}$ grain size followed by $0.15 \mathrm{~mm}$, mixed grain and coarse grain $1.18 \mathrm{~mm}$ specimens (figure $4 \mathrm{c}$ ). The $\mathrm{CaCO}_{3}$ content varied from $6.2-8.8 \%$ of final dry weight. It has been seen that compressive strength was exponentially related to carbonate content in all specimens which is in line with the previous published results of Van Paassen et al (2010).

The results indicate that there is an optimum grain size for maximising carbonate precipitation. The tradeoff lies between delivering the cementation fluid uniformly in the whole of the specimen while blocking the pore spaces. In larger grain sizes the voids are too large to retain the cementation fluid fpor precipitation. In smaller grain sizes the voids in the top half of the column tend to get plugged prematurely, thus blocking the path of the cementation fluid to the bottom half. In the current study, $0.425 \mathrm{~mm}$ grain size is found to perform optimally. Current results are in accordance with our recent study wherein we found that grain size plays a very crucial role in deciding the success and efficacy of MICP (Dhami et al., 2016). This experiment clearly demonstrates the unsuitability of grains larger than $1 \mathrm{~mm}$ for MICP.

\section{Effect of curing method:}

Another way of circumventing the fluid distribution problem is to minimise the channel length through a vascular design. Figure 6 presents the effect of curing methods on the efficacy of bio cementation. In this case UPV varied in a much closer range ( 310 to $395 \mathrm{~m} / \mathrm{s}$ ) signifying better consolidation in the vascular curing in comparison to the column curing. Highest velocity was seen in case of BC2 specimens wherein cementation fluid was supplied from inner injection as well as outer spray resulting in the least channel length $(11.25 \mathrm{~mm})$. BC1 (spraying) and BC3 (immersion) where the curing was through the outer surface had a higher channel length pf $25 \mathrm{~mm}$. Clearly, minimization of channel length leads to maximization of consolidation.

The UCS test also indicated the significance of mode of curing. The range of UCS in vascular curing was between 524 and $757 \mathrm{kPa}$, considerably higher than column curing. However, the highest strength was noticed in case of $\mathrm{BC} 1$ specimens rather than in $\mathrm{BC} 2$ with the least channel length. It may be noted that $\mathrm{BC} 2$ had an annular cross-section with a hole in the centre of the column while $\mathrm{Bc} 1$ and $\mathrm{BC} 3$ were solid cylinders. Thus, UCS results would be affected by the difference in cross-section. The estimation of calcite may be a better indicator of homogeneity in the deposition.
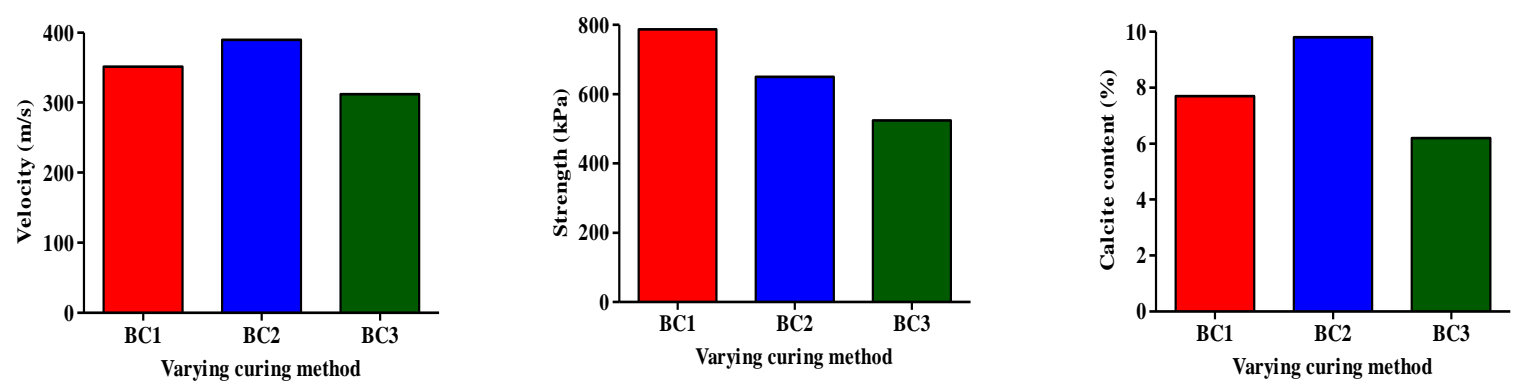

Figure 6. Effect of varying curing methods on MICP as per a) UPV b) UCS c) Calcite content 
The estimation of calcite demonstrated that $\mathrm{BC} 2$ specimens had 9.8\% deposition, which is considerably higher than any other samples. This confirmed that more uniform carbonate precipitation can be achieved through minimization of channel length. Clearly, one of the fundamental factors in quantity and uniformity of calcite deposition is the channel length. BC2 specimens have higher contacts between cells and cementation fluid within sand grains enabling better utilization of cementation chemicals and minimization of wastage. Minimization of channel length can obviate the necessity of a pressurized system for the flow of CF using pumps, thus economizing the process.

\section{Effect of stabilizer}

Figure 7 represents the effect of stabilizer on MICP in varying grain size sand columns. Addition of $6 \%$ cement stabilizer was found to improve the efficacy of MICP significantly. UPV of stabilizer only samples varied in the range of 290 to $352 \mathrm{~m} / \mathrm{s}$, while stabiliser with MICP samples had a UPV range between 324 and $450 \mathrm{~m} / \mathrm{s}$. Thus it is clear that MICP improves the consolidation of cement stabilized samples. The stabilized samples had considerably higher UPV than the unstabilized samples (Figure 4) proving the efficacy of stabilization. In this case too, the UPV was higher in fine grain samples than the coarse and mix grain samples.
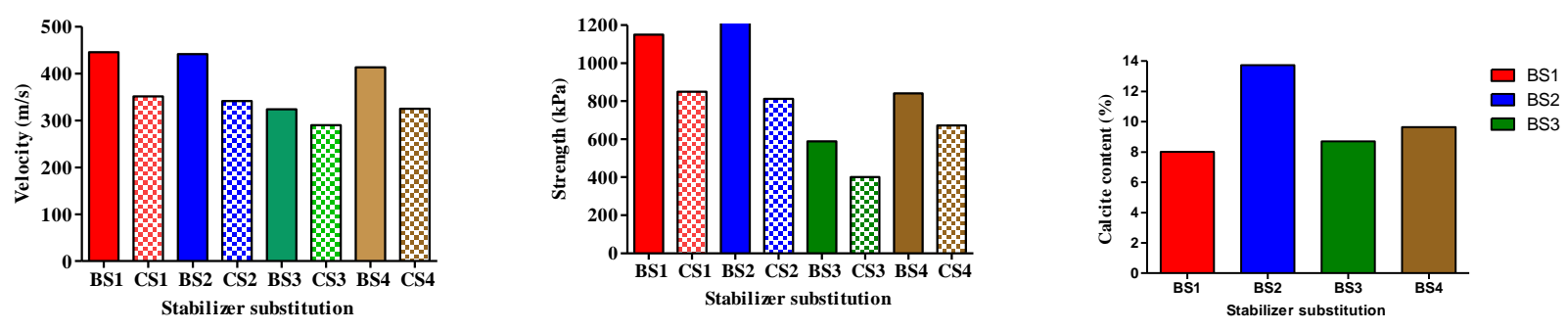

Figure 7. Effect of stabilizer on MICP a) UPV b) UCS c) Calcite content

In UCS tests, a remarkable improvement was noticed due to stabilization. The UCS more than doubled in stabilized samples compared to the unstabilized ones (Figure 4). A large improvement in strength could be achieved cement stabilized MICP samples in comparison to just cement samples. In this case too, highest strength was achieved in case of BS2 followed by BS1, BS4 and BS3. The combined strength of MICP and stabilizer sets was much higher than the individual strength by MICP and cement addition alone in all cases. This remarkable improvement in the combined stabilizer with MICP sets could be due to the improvement in stability of pore structure due to cementation that allowed easier access of cementation fluid and further reinforcement in bonding through deposition of carbonates in between contact points of sand grains. Understandably, the carbonate content in these samples are higher than the nonstabilized ones. The results indicate a huge bonus in stabilizing the sand grains to optimally utilize the benefits of MICP.

\section{Micrographs, EDS and XRD}

Microstructural analysis of biocemented sand columns was performed to discern the locations of deposition of calcite crystals. SEM coupled with EDX as well as with XRD analysis have been presented in figure 8 . SEM analysis clearly depicted the formation of crystals in between the sand grains helping in their bonding while EDS revealed the presence of high amounts of calcium and carbon along with sand components, silica and oxygen. Formation of crystals in between the sand grains confirmed the selective precipitation, which reinforces the material by preventing intergranular slip or rotation. The bacterial cells secure themselves at the acute corners that nucleates mineralization at strategic locations. XRD of the samples revealed the that majority of carbonate deposits were present as calcite along with sand components silica and quartz. 

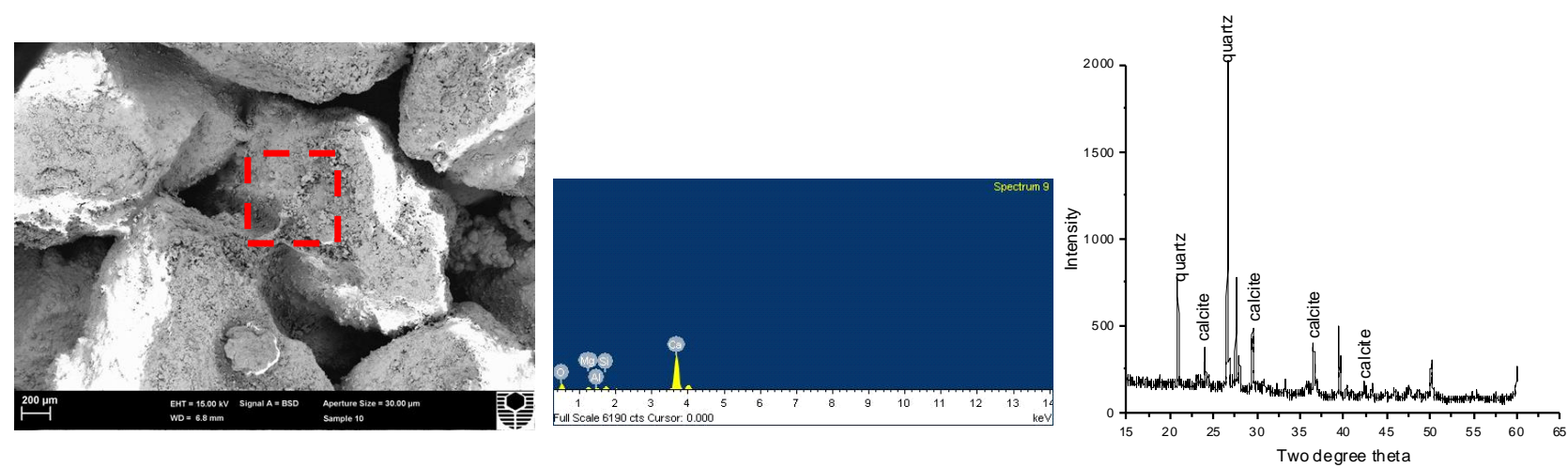

Figure 8. SEM, EDS and XRD of MICP samples

\section{CONCLUSION}

This study explores maximisation of MICP in granular materials by controlling the grain size, the method of curing and stabilization. Key conclusions drawn from this study are:

1. For aggregated granular materials UPV is reliable and can be calibrated to UCS.

2. Optimal grain size is around $0.5 \mathrm{~mm}$ for maximizing MICP.

3. Minimising channel length through vascular designs delivers a homogenous MICP resulting in economy.

4. Cement stabilization dramatically improves the consolidation power of MICP

\section{REFERENCES}

Achal, V., Mukherjee, A., Basu, P. C., and Reddy, M. S. (2009). "Lactose mother liquor as an alternative nutrient source for microbial concrete production by Sporosarcina pasteurii." Journal of industrial microbiology \& biotechnology, 36(3), 433-438.

Achal, V., Mukherjee, A., Goyal, S., and Reddy, M. S. (2012). "Corrosion Prevention of Reinforced Concrete with Microbial Calcite Precipitation." Aci Materials Journal, 109(2), 157-163.

Achal, V., Mukherjee, A., Kumari, D., and Zhang, Q. (2015). "Biomineralization for sustainable construction - A review of processes and applications." Earth-Science Reviews, 148, 1-17.

Achal, V., Mukherjee, A., and Reddy, M. S. (2011). "Microbial Concrete: Way to Enhance the Durability of Building Structures." Journal of Materials in Civil Engineering, 23(6), 730-734.

AS (2010). "AS3972 - General purpose and blended cements." Standards Australia, Sydney, NSW, Australia.

Castanier, S., Le Métayer-Levrel, G., and Perthuisot, J.-P. (1999). "Ca-carbonates precipitation and limestone genesis - the microbiogeologist point of view." Sedimentary Geology, 126(14), 9-23.

Cheng, L., Cord-Ruwisch, R., and Shahin, M. A. (2013). "Cementation of sand soil by microbially induced calcite precipitation at various degrees of saturation." Canadian Geotechnical Journal, 50(1), 81-90.

Chu, J., Stabnikov, V., and Ivanov, V. (2012). "Microbially Induced Calcium Carbonate 
Precipitation on Surface or in the Bulk of Soil." Geomicrobiology Journal, 29(6), 544-549.

Dejong, J., Burbank, M., Kavazanjian, E., Weaver, T., Montoya, B., Hamdan, N., Bang, S., Esnault-Filet, A., Tsesarsky, M., Aydilek, A., Ciurli, S., Tanyu, B., Manning, D. A. C., Larrahondo, J., Soga, K., Chu, J., Cheng, X., Kuo, M., Al Qabany, A., Seagren, E. A., Van Paassen, L. A., Renforth, P., Laloui, L., Nelson, D. C., Hata, T., Burns, S., Chen, C. Y., Caslake, L. F., Fauriel, S., Jefferis, S., Santamarina, J. C., Inagaki, Y., Martinez, B., and Palomino, A. (2013). "Biogeochemical processes and geotechnical applications: progress, opportunities and challenges." Géotechnique, 63(4), 287-301.

Dhami, N. K., Reddy, M. S., and Mukherjee, A. (2012). "Bacillus megaterium mediated mineralization of calcium carbonate as biogenic surface treatment of green building materials."

Dhami, N. K., Reddy, M. S., and Mukherjee, A. (2012). "Biofilm and Microbial Applications in Biomineralized Concrete." In Advanced Topics in Biomineralization (Ed. Jong Seto) InTech, 137-164.

Dhami, N. K., Reddy, M. S., and Mukherjee, A. (2012). "Improvement in strength properties of ash bricks by bacterial calcite." Ecological Engineering, 39, 31-35.

Dhami, N. K., Reddy, M. S., and Mukherjee, A. (2013). "Biomineralization of calcium carbonates and their engineered applications: a review." Frontiers in microbiology, 4, 314.

Dhami, N. K., Reddy, M. S., and Mukherjee, A. (2016). "Significant indicators for biomineralisation in sand of varying grain sizes." Construction and Building Materials, 104, 198-207.

Hammes, F., and Verstraete, W. (2002). "Key roles of pH and calcium metabolism in microbial carbonate precipitation." Reviews in environmental Science and Biotechnology, 1, 3-7.

Montoya, B., and DeJong, J. (2015). "Stress-Strain Behavior of Sands Cemented by Microbially Induced Calcite Precipitation." Journal of Geotechnical Geoenvironmental Engineering, 141(6).

Rusznyak, A., Akob, D. M., Nietzsche, S., Eusterhues, K., Totsche, K. U., Neu, T. R., Frosch, T., Popp, J., Keiner, R., Geletneky, J., Katzschmann, L., Schulze, E. D., and Kusel, K. (2012). "Calcite biomineralization by bacterial isolates from the recently discovered pristine karstic herrenberg cave." Applied and environmental microbiology, 78(4), 1157-1167.

Spadafora, A., Perri, E., McKenzie, J. A., and Vasconcelos, C. G. (2010). "Microbial biomineralization processes forming modern $\mathrm{Ca}: \mathrm{Mg}$ carbonate stromatolites." Sedimentology, 57(1), 27-40.

Whiffin, V. S., van Paassen, L. A., and Harkes, M. P. (2007). "Microbial Carbonate Precipitation as a Soil Improvement Technique." Geomicrobiology Journal, 24(5), 417-423.

Yang, Z., and Cheng, X. (2013). "A performance study of high-strength microbial mortar produced by low pressure grouting for the reinforcement of deteriorated masonry structures." Construction and Building Materials, 41, 505-515. 